\title{
Properties and Interfacial Interaction of Epoxidized Natural Rubber/ Precipitated Silica Composites
}

\author{
Yueqiong Wang ${ }^{1, a}$, Lusheng Liao ${ }^{1, b^{*}}$, Bingbing Wang ${ }^{1, c}$, Fuquan Zhang ${ }^{1, d}$, \\ Jieping Zhong ${ }^{2, \mathrm{e}}$, Kui $\mathrm{Xu}^{1 \mathrm{f}}$, Zheng Peng ${ }^{1, \mathrm{~g}}$ and Puwang $\mathrm{Li}^{1, \mathrm{~h}}$
}

${ }^{1}$ Agricultural Products Processing Research Institute, Chinese Academy of Tropical Agricultural Sciences, Zhanjiang 524001 P. R. China

\author{
${ }^{2}$ School of Science, Guangdong Ocean University, Zhanjiang 524088 P. R. China

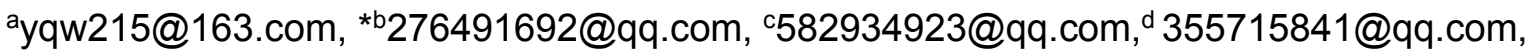 \\ ezhongjieping0303@163.com, ${ }^{\mathrm{f}}$ kuixu9981@163.com, ${ }^{\mathrm{g}}$ zpengcatas@126.com, ${ }^{\mathrm{h}}$ puwangli@163.com
}

Keywords: interaction, epoxidized natural rubber, precipitated silica, composites

Abstract. ENR40/ precipitated silica (P-silica) compounds were prepared by in an open two-roll laboratory mixing mill at $50 \sim 60{ }^{\circ} \mathrm{C}$. Curing properties and mechanical properties was investigated. In order to reveal the interaction between ENR40 and P-silica, ENR40/P-silica compounds were extracted in toluene to obtain the bonding rubber content. Interfacial interaction of ENR40/P-silica was investigated by Fourier transform infrared spectroscopy (FTIR). The results indicated that during mixing process, ENR and silica had hydrogen bond and chemical interaction.

\section{Introduction}

It is well known that epoxidized natural rubber (ENR) is prepared by the epoxidized reaction of natural rubber (NR) in peracid conditions as a modified rubber ${ }^{[1,2]}$. The reaction not only makes ENR leave some properties of NR, but also makes ENR possess new properties which are different from the normal characteristics of NR, such as oil resistance, gas tightness ${ }^{[3,4]}$, low rolling resistance ${ }^{[5]}$, high wet skid resistance and the potential interaction with other polymers and fillers. The properties are useful in tires and other rubber products. It is shown that the ENR could be a good matrix in rubber industry ${ }^{[6]}$.

Silica which is one of the most important reinforcing filler, is usually been considered as the best filler in "green tire" since the beginning of the 1990s. Silica was used to fill in styrene-butadiene rubber (SBR) in tires that had improvement rolling resistance and wet skidding resistance. Moreover, silica was usually used together with silane coupling agents, for example bis-(3-triethoxysilylpropyl) tetrasulfane (Si-69) to improve the dispersion in SBR matrix and properties is successful in tire industry.

However, in NR matrix, the technology of improving silica dispersion by Si-69 is unsuccessful because of the non-rubber component in $\mathrm{NR}^{[7]}$, leading to less use of silica content in truck tires ${ }^{[8]}$. Therefore, ENR not only has good elastic properties, but also has special properties that be used as compatibilizer. ENR becomes a new material that is considered to be used in high performance tires. There already have been reported that Sumitomo Rubber Industries in Japan had manufactured significant performance tire by ENR ${ }^{[9]}$.

There are many papers to research interfacial interaction between elastomer and filler such as carbon black, silica, clay, while study on interaction between ENR matrix and silica compounds are still has not definitely concepted.

In this article, ENR40/P-silica compounds were prepared. To investigate compounds interaction, bonding rubbers were obtained by extraction for 72 hours. Compounds of ENR40/P-silica were test by Fourier trans-form infrared spectroscopy (FTIR), results showed that with the increment of silica content, bonding rubber increases. There is definitely hydrogen bond and new chemical bond conformed during mechanical mixing. 


\section{Experiment and Characterizations}

Materials. The ENR used in this study was ENR-40, having $40 \mathrm{~mol} / \%$ of the double bonds epoxidation, which was prepared by Agricultural Products Processing Research Institute, Chinese Academy of Tropical Agricultural Sciences. Precipitated silica 255 was provided by Nanji chemical industry Co., LTD, Nanchang, Jiangxi Province, China. Other additives used were industrial grades. The formulation of composites (parts per hundreds of rubber) : Zink oxide $4 \mathrm{phr}$, Stearic acid $2 \mathrm{phr}$, accelerator CZ $1.5 \mathrm{phr}$, accelerator DM $0.5 \mathrm{phr}$, Sulfur $1.5 \mathrm{phr}$, P-silica 0, 10phr, 20phr, 30phr, 40phr, 50phr. ENR-40 100 phr.

Preparation of ENR40/P-silica compounds. ENR40/P-silica compounds with different silica content were prepared in an open two-roll mixing mill at $50 \sim 60^{\circ} \mathrm{C}$ for about 15 minutes. ENR40 was milled for 2 minutes, silica was added after. Then, the curatives were added to the compound. After about 5 minutes' mixing, compounds film with $4 \mathrm{~mm}$ thickness were prepared.

Optimum cure times were measured with $4 \mathrm{~g}$ compound on an Alpha Moving Die Rheometer at $150{ }^{\circ} \mathrm{C}$. Vulcanization was carried out on an electrically heated machine, at $150{ }^{\circ} \mathrm{C}$, for the optimum time. Then, rubber films with $2 \mathrm{~mm}$ thickness were obtained.

Curing properties. Curing properties were carried out on an Alpha Moving Die Rheometer at 150 ${ }^{\circ} \mathrm{C}$ for 20 minutes. The optimum curing times and max torque and min torque were obtained.

Mechanical properties. The tensile strength data were tested according to Chinese standard GB/T528 with an UT-2060 tensile instrument using C-type dumbbell samples. The stress and strain were obtained from the test.

Determination of bonding rubber. $2 \mathrm{~g}$ rubber compound was divided into scraps and packaged with 200 mesh metal net, then immersed in toluene for $72 \mathrm{~h}$. Then, the compounds were dried to a constant weight in vacuum oven. The bonding rubber content was calculated as Eq. 1.

Bonding rubber content (mass $\%)=\left[\mathrm{W}_{0}-\left(\mathrm{W}_{1}-\mathrm{W}_{2}\right)\right] / \mathrm{W}_{0} \times 100 \%$

In Eq. $1, \mathrm{~W}_{0}$ is the rubber mass of the sample, $\mathrm{W}_{1}$ is the sample quality including metal net, and $\mathrm{W}_{2}$ is the sample quality including metal net after drying

Fourier transformation infrared spectroscopy. (FTIR). ENR40/P-silica compounds were operated in the transmission mode and attenuated total reflectance Fourier transform infrared spectroscopy. P-silica was performed by transmission mode.

\section{Results and Discussion}

Influence of P-silica content on cure parameters. Table 1 is the values of scorch time, optimum cure time, minimum torque and maximum torque of ENR40/P-silica compounds.

Table 1 Cure Parameters of ENR40/P-silica Compounds with Different Silica Content

\begin{tabular}{cccccc}
\hline $\begin{array}{c}\text { P-silica } \\
\text { content } \\
{[\mathrm{phr}]}\end{array}$ & $\begin{array}{c}\text { Scorch Time } \\
\mathrm{t}_{\mathrm{s} 1} \\
{[\mathrm{~min}]}\end{array}$ & $\begin{array}{c}\text { Optimum Cure } \\
\text { Time } t_{90} \\
{[\mathrm{~min}]}\end{array}$ & $\begin{array}{c}\text { Minimum } \\
\text { Torque } \\
{[\mathrm{dN} \cdot \mathrm{m}]}\end{array}$ & $\begin{array}{c}\text { Maximum } \\
\text { Torque } \\
{[\mathrm{dN} \cdot \mathrm{m}]}\end{array}$ & $\begin{array}{c}\text { Max } \\
\text { Torque -Min } \\
\text { Torque } \\
{[\mathrm{dN} \cdot \mathrm{m}]}\end{array}$ \\
\hline 0 & 1.24 & 3.52 & 0.32 & 6.84 & 6.52 \\
10 & 1.46 & 4.07 & 0.45 & 8.62 & 8.17 \\
20 & 2.02 & 5.04 & 0.72 & 11.02 & 10.29 \\
30 & 2.14 & 6.44 & 1.35 & 15.36 & 14.01 \\
40 & 2.30 & 8.11 & 2.65 & 24.91 & 22.26 \\
50 & 2.15 & 9.09 & 4.50 & 34.76 & 30.26 \\
\hline
\end{tabular}

As showed in Table 1, the optimum curing time and scorch time of ENR40/P-silica compounds increased with increment amount of P-silica. The scorch time and optimum cure time had relationship 
with the fillers properties, for example, particle size, specific surface area, moisture content. So the scorch time and optimum time were less than the compounds with the fumed silica that have studied in previous research ${ }^{[10]}$. That was because precipitated silica had bigger particle size and lower surface area, and didn't absorb more accelerant. As a result, precipitated silica didn't retard the cure process so much.

The maximum torque was increasing with the P-silica content increased. That was because crosslink densities were enhanced with the P-silica content increased. When there was more silica existed, ENR40 and silica will have more interaction between filler and molecular chain, which will block the macromolecular chains moving. Therefore, the maximum torque increased.

Mechanical properties of ENR40/P-silica composites. Table 2 was the mechanical properties of ENR40/P-silica composites. It is obvious that stress at $100 \%$ and $300 \%$ was increased with the P-silica content increment. The elongation at break of the composites increased at $10 \mathrm{phr}$, while decreased when P-silica content was more than 10phr. Tensile strength of ENR40/P-silica composites appeared maximum at $10 \mathrm{phr}$, when P-silica content was more than $10 \mathrm{phr}$, tensile strength decreased. And the tear strength appears maximum at 20phr. That was because P-silica had bigger particles, when there was more than $10 \mathrm{phr}$ content, the particle would aggregated and lowered the reinforcement effect.

Table 2 Mechanical properties of ENR40/P-silica composites

\begin{tabular}{cccccc}
\hline $\begin{array}{c}\text { P-silica } \\
\text { content [ phr] }\end{array}$ & $\begin{array}{c}\text { Stress at } \\
100 \%[\mathrm{MPa}]\end{array}$ & $\begin{array}{c}\text { Stress at } \\
300 \%[\mathrm{MPa}]\end{array}$ & $\begin{array}{c}\text { Elongation at } \\
\text { break [\%] }\end{array}$ & $\begin{array}{c}\text { Tensile Strength } \\
{[\mathrm{MPa}]}\end{array}$ & $\begin{array}{c}\text { Tear Strength } \\
{\left[\mathrm{kN} . \mathrm{m}^{-1}\right]}\end{array}$ \\
\hline 0 & 0.87 & 1.98 & 740 & 30.6 & 30.3 \\
10 & 1.10 & 2.80 & 760 & 33.08 & 54.5 \\
20 & 1.40 & 4.00 & 733 & 30.23 & 92.9 \\
30 & 1.92 & 5.73 & 670 & 23.78 & 87.8 \\
40 & 2.19 & 6.11 & 592 & 16.65 & 68.4 \\
50 & 3.23 & 7.11 & 602 & 14.80 & 41.3 \\
\hline
\end{tabular}

Bonding rubber content. Table 3 was the bonding rubber content of ENR40/P-silica compounds. The bonding rubber content could reflect the reaction between filler and matrix. It was obvious that the bonding rubber content increased with P-silica content increased, that means that there was chemical reaction between silica and ENR40 matrix.

Table 3 Bonding rubber content of ENR40/P-silica compounds

\begin{tabular}{ccccccc}
\hline P-silica content [ phr] & 0 & 10 & 20 & 30 & 40 & 50 \\
\hline $\begin{array}{c}\text { Bonding rubber } \\
\text { content[\%] }\end{array}$ & 0 & 2.15 & 7.15 & 17.13 & 24.05 & 32.85 \\
\hline
\end{tabular}

FTIR of ENR40/P-silica compounds. Fig. 1 was the FTIR curves of ENR40/P-silica compounds that hadn't been cured. From the infrared spectrum of P-silica, $1108 \mathrm{~cm}^{-1}$ peak arises from Si-O-Si asymmetrical stretching vibration and the absorption peak at $804 \mathrm{~cm}^{-1}$ is the symmetrical stretching vibration of $\mathrm{Si}-\mathrm{O}^{[11]}$. In ENR40/P-silica compounds, $872 \mathrm{~cm}^{-1}$ and $832 \mathrm{~cm}^{-1}$ stand for the asymmetrical stretching vibration of epoxy ring. Si-O-Si asymmetrical stretching vibration of P-silica in ENR40/P-silica compounds moved from $1108 \mathrm{~cm}^{-1}$ to $1075 \mathrm{~cm}^{-1}$ and symmetrical stretching vibration of Si-O at $804 \mathrm{~cm}^{-1}$ moved to $799 \mathrm{~cm}^{-1}$, which means there is hydrogen bond appeared at $\mathrm{Si}-\mathrm{O}-\mathrm{Si}$ during mixing. There is also phenomenon that asymmetrical stretching vibration of epoxy ring at $832 \mathrm{~cm}^{-1}$ became disappear with P-silica content increase, while symmetrical vibration of Si-O at $798 \mathrm{~cm}^{-1}$ became larger. That may be because there was ring open during mixing, that decreased the epoxy ring and conform Si-O-C bond. 


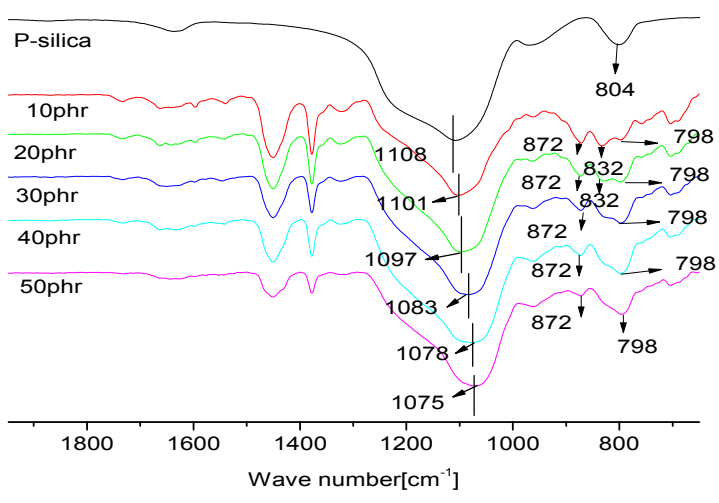

Fig. 1 FTIR curves of ENR40/P-silica compounds and P-silica

\section{Conclusions}

ENR40/P-silica compounds with different P-silica content had been prepared by mechanical method. Curing properties and mechanical properties had been studied. The maximum torque and optimum curing time increased with P-silica increasing. Bonding rubber had been investigated, and bonding rubber content grew with P-silica content increased. Interfacial interaction between ENR40 and P-silica had been carried out by FTIR, results showed that there was epoxy ring open during mixing, and there were hydrogen bond and Si-O-C bond conformed between ENR40 and P-silica.

\section{Acknowledgements}

This work was financially supported by Special Fund for Agro-scientific Research in the Public Interest (NO. 201403066), the Earmarked Fund for China Agriculture Research System (NO. CARS-34-JG2), the Natural Science Foundation of Hainan Province (NO. 2017CXTD017) and Funded by Central Public-interest Scientific Institution Basal Research Fund for Chinese Academy of Tropical Agricultural Sciences (No.1630122017005).

\section{References}

[1] Baker, C. S. L.; Gelling, I. R.; Newell, R., Elastomerics Vol. 116 (1984), p. 23

[2] Hashim, A. S.; Kohjiya, S., Kautschuk Gummi Kunststoffe Vol. 46(1993), p. 208

[3] Barrie, J. A.; Becht, M.; Campbell, D. S., Polymer Vol. 33(1992), p. 2450

[4] Johnson, T.; Thomas, S., Journal of Macromolecular Science-Physics B Vol. 36(1997), p. 401

[5] Burfield, D. R.; Lim, K.-L.; Law, K.-S., J. Appl. Polym. Sci. Vol. 29(1984), p. 1661

[6] Sengloyluan, K.; Sahakaro, K.; Dierkes, W. K.; Noordermeer, J. W. M., Eur. Polym. J. Vol. 51(2014), p. 69

[7] Sarkawi, S. S., Kautschuk und Gummi Kunststoffe Vol. 66(2013), p. 27

[8] Anke Blume; Janine Fähr; Clément Morisse, Rubber World Vol. 246(2012), p. 24

[9] Cook, S., Materials World Vol. 17(2009), p. 30

[10]Luo, Y. Y.; Wang, Y. Q.; Zhong, J. P.; He, C. Z.; Li, Y. Z.; Peng, Z., Journal of Inorganic and Organometallic Polymers and Materials Vol. 21(2011), p. 777

[11]Xu, T.; Jia, Z.; Luo, Y.; Jia, D.; Peng, Z., Appl. Surf. Sci. Vol. 328(2015), p. 306 